\title{
Trypanosoma cruzi: requirements for induction and maintenance of protective immunity conferred by immunization
}

\author{
Cláudia N. Paiva, ${ }^{\mathrm{a}, 1,2}$ Alexandre S. Pyrrho, ${ }^{\mathrm{a}, \mathrm{b}}$ Liane J. Ribeiro, ${ }^{\mathrm{a}}$ Renata Gonçalves, ${ }^{\mathrm{a}}$ \\ Deise A. Costa, ${ }^{\mathrm{a}}$ Tania C. Araujo-Jorge, ${ }^{\mathrm{c}}$ Milena B.P. Soares, ${ }^{\mathrm{a}, \mathrm{d}}$ and Cerli R. Gattass ${ }^{\mathrm{a}, *}$ \\ ${ }^{a}$ Laboratório de Imunoparasitologia, Instituto de Biofísica Carlos Chagas Filho, Universidade Federal do Rio de Janeiro, \\ 21941-900 Rio de Janeiro, RJ, Brazil \\ b DACT, Faculdade de Farmácia, UFRJ, Rio de Janeiro, RJ, Brazil \\ ${ }^{\mathrm{c}}$ Instituto Oswaldo Cruz/LBC-DUBC, FIOCRUZ, Rio de Janeiro, RJ, Brazil \\ ${ }^{\mathrm{d}}$ Centro de Pesquisas Gonçalo Moniz, FIOCRUZ, Salvador, BA, Brazil
}

Received 7 February 2002; received in revised form 3 September 2002; accepted 18 February 2003

\begin{abstract}
Immunization with CL-14-trypomastigotes generates efficient humoral and cellular responses against infective challenge. Herein, we investigated the relevance of these mechanisms in vivo. Immunization with live CL-14-trypomastigotes protected only part of $\beta 2 \mathrm{~m}^{-/-}$mice but efficiently protected perforin-knockout mice. Fixed CL-14-trypomastigotes could successfully immunize BALB/c, though live trypomastigotes lowered the requirements for doses and time intervals. Post-immune depletion of CD4 or CD8 subsets did not affect protection conferred by immunization, but switched the production of anti-Trypanosoma cruzi antibodies to IgG2a. Sublethal irradiation partially broke the resistance of immune mice, leading to development of late parasitemia. Passive serum transfer from immune mice conferred protection to naïve mice. Our results indicate that presentation of cytosolic antigens by MHC class I molecules is involved in the generation of immunity and suggest that the humoral response contributes to a great extent to keep CL-14-immunized mice protected against infective challenge.
\end{abstract}

(C) 2003 Elsevier Science (USA). All rights reserved.

\section{Introduction}

Trypanosoma cruzi is the etiologic agent of Chagas' disease, a lifelong health problem to which there is no immunoprophylaxis or chemotherapeutic cure. The parasite proliferates actively after contamination, but only children have marked symptoms of disease. Infected individuals control acute infection and progress to an asymptomatic phase, but fail to eliminate the parasite. A proportion of them develop cardiac and/or digestive disease many years after contamination, while

\footnotetext{
${ }^{*}$ Corresponding author. Fax: +55-21-2239-1513.

E-mail addresses: cnpaiva@iname.com (C.N. Paiva), cerli@chagas.biof.ufrj.br (C.R. Gattass).

${ }^{1}$ Present address: Departamento de Imunologia, Instituto de Microbiologia Paulo de Góes, Universidade Federal do Rio de Janeiro, 21941-900 Rio de Janeiro, Brazil.

${ }^{2}$ Also corresponding author.
}

the majority remain asymptomatic (Ribeiro-dos-Santos et al., 1981). Most of our knowledge about the mechanisms of protection against acute $T$. cruzi infection comes from murine experimental infection. The control of acute infection in mice is known to involve the participation of many cellular types and effector mechanisms (DosReis, 1997). Nevertheless, little is known about the mechanisms activated by immunization against $T$. cruzi.

The activation of $\mathrm{CD} 8$ cells seems to be a fundamental response in various models of immunization against $T$. cruzi (Tarleton, 1990). In a previous study, immunization with an avirulent strain failed to protect $\beta 2$-microglobulin and TAP-1 knockout mice against infective challenge, while perforin- and granzime Bknockout mice benefited from immunization (Kumar and Tarleton, 1998). In fact, the identification of CD8restricted protective CTL epitopes from $T$. cruzi TSA-1 protein allowed the development of an effective experimental DNA vaccine (Wizel et al., 1997). Likewise, the 
humoral immunity induced by immunization can mediate protection (Araguth et al., 1988; Araujo and Morein, 1991; Gonzalez et al., 1991; Umezawa et al., 1993), and was shown to be required for immunization with an avirulent $T$. cruzi clone (Kumar and Tarleton, 1998). On the other hand, CD4 T1 cells generated by immunization are trypanocidal in vitro (Quanquin et al., 1999; Rodrigues et al., 1999), but its relevance as a protective mechanism in vivo remains to be demonstrated. Recently, CD4 trypanocidal cells were generated by Th1biased immunization with $T$. cruzi lysates, but could not transfer immunity and were not required to adoptive transfer of immunity to Scid mice (Hoft et al., 2000). These results evidence the need to evaluate the contribution of each mechanism to immunity in vivo, in order to design efficient vaccines. Such an effort was done by Miller et al., which showed that survival conferred by immunization with $T$. cruzi paraflagellar rod protein required MHC class I antigenic presentation and IFN- $\gamma$ production, but not B or CD4 cells (Miller et al., 1997), despite the induction of IgG1 antibodies (Miller et al., 1996) and parasitemia-controlling T1 CD4 cells (Miller et al., 1997).

CL-14 is a clone obtained from the CL strain that presents very unusual properties for a $T$. cruzi. Injection of live CL-14-trypomastigotes induces neither patent infection (Lima et al., 1991) nor histopathological lesions or cellular infiltration (Lima et al., 1995). Nevertheless, it brings about a strong immune response against T. cruzi Y and CL strains (Lima et al., 1991; Paiva et al., 1999a) that totally prevents development of patent parasitemia or mortality after infective challenge. The resistance of CL-14-immunized mice to polyclonal T lymphocyte activation imposed by $T$. cruzi probably contributes to their focused cellular immune response against infective challenge (Paiva et al., 1999b). Adoptive transfer studies demonstrated a protective CD8 recall response to challenge in CL-14-immunized mice (Paiva et al., 1999a). In addition, immunized mice mount a strong humoral response against the parasite dominated by high titers of anti- $T$. cruzi IgG1 and IgG2a (Pyrrho et al., 1998). Herein, we sought to investigate in vivo the contribution of various mechanisms that act to induce and maintain an immune state in mice after inoculation with CL-14 trypomastigotes.

\section{Materials and methods}

\subsection{Mice and parasites}

32-Microglobulin knockout BALB/c mice $\left(\mathrm{H}-2^{\mathrm{d}}\right)$ were used under permission from Dr. Robert Dubridge (Lynx Therapeutics Inc., Hayward, CA, USA). Perforin-knockout mice (P0, H-2 ${ }^{\text {b }}$ (Walsh et al., 1994) were maintained at Instituto Oswaldo Cruz animal facilities (FIOCRUZ, Rio de Janeiro). CL-14 (Chiari, 1981) and CL epimastigotes (Brener and Chiari, 1963) were maintained in axenic cultures and subjected to metacyclogenesis in vitro. Trypomastigotes were purified by DEAE-chromatography (Lima et al., 1991). Immunization with CL-14 was performed by i.p. inoculation with $2 \times 10^{6}-10^{7}$ live trypomastigotes or $10^{7}-10^{8}$ fixed CL-14-trypomastigotes in $0.2 \mathrm{ml}$ PBS (priming doses, booster doses, and time intervals before challenge are indicated in legends). Fixed CL-14-trypomastigotes were obtained by incubating pellets of $10^{9}$ CL-14-trypomastigotes in $1 \mathrm{ml}$ of $1 \%$ formaldehyde-PBS for $1 \mathrm{~min}$ and then washing parasites in PBS. CL strain trypomastigotes were maintained by serial blood passage and used to challenge mice in all experiments (i.p.). Parasitemia levels were evaluated by Brener's method (Brener, 1962) and 500 fields were counted per section.

\subsection{In vivo post-immune depletion of CD4 and CD8 subsets}

Hyperimmunized BALB/c female mice received $0.5 \mathrm{mg}$ of purified anti-CD8 (53.6.7) or anti-CD4 (GK1.5) i.p. on days 4,3 , and 2 before challenge. On a second experiment, hyperimmunized $\mathrm{BALB} / \mathrm{c}$ male mice received either $0.5 \mathrm{ml}$ ascites anti-CD8 (2.43) i.p. on days 2, 1 , and $1 \mathrm{~h}$ before challenge or $0.5 \mathrm{mg}$ of purified anti-CD4 (GK1.5) on day 2 and $0.3 \mathrm{mg}$ anti-CD4 (RL-172) on day 1 and $1 \mathrm{~h}$ before challenge. Depletion of $\mathrm{T}$ cell subsets was monitored by flow cytometry using anti-CD4PE (H129.19) or -CD8a-PE (53-6.7), purchased from Pharmingen (San Diego, CA), and both protocols were found to eliminate most of the cells $(92-98 \%)$ of the desired subset.

\subsection{ELISA for anti-T. cruzi immunoglobulin plasma titers}

Suspensions of $10^{8} \mathrm{CL}$ strain parasites $/ \mathrm{ml}$ (obtained from infected LCCK cell cultures) were submitted to 10 freeze-and-thaw cycles and $100 \mu 1$ of this antigenic solution were incubated per well in $0.01 \mathrm{M}$ sodium carbonate, $\mathrm{pH} 9.2$, in a 96 microtiter plate overnight at $4^{\circ} \mathrm{C}$. After washing, $50 \mu \mathrm{l}$ of diluted plasma samples (1/ $20-1 / 12500$, duplicate) were incubated for $8 \mathrm{~h}$ at $4{ }^{\circ} \mathrm{C}$. Plates were then washed with $0.05 \%$ Tween $20-$ PBS and incubated with diluted (1/2000) isotype-specific anti-mouse $\mathrm{IgG} 1$ and $\mathrm{IgG} 2 \mathrm{a}$ conjugated to alkaline phosphatase (Southern Biotechnology Associates, Birmingham, Ala) to reveal bound antibodies. After further washing, assays were developed with p-NPP (Zymed, San Francisco, CA, USA) and read under a $410 \mathrm{~nm}$ filter in a Bio-Rad (Richmond, CA, USA) microplate reader (3550-UV). 


\subsection{Total body irradiation and bone marrow transplan- tation}

Total body irradiation of $600 \mathrm{rad}$ was carried out using a ${ }^{60} \mathrm{Co}(18 \mathrm{rad} / \mathrm{min})$ source, while $515 \mathrm{rad}$ were delivered by a ${ }^{137} \mathrm{Cs} \gamma$-ray source $(258 \mathrm{rad} / \mathrm{min})$. Mice were then kept under asseptic conditions. Bone marrow cells from normal young syngeneic donors were obtained by flushing femur and tibia marrows with RPMI. Viable cells from bone marrow suspensions were counted by trypan blue exclusion in a Neubauer chamber and $2 \times 10^{7}$ cells were transferred i.p. to each receptor.

\subsection{Passive serum transfer}

Hyperimmunized and age-matched normal mice were used as blood donors. Five hundred microliters of serum was transferred i.p. to naïve receptors $1 \mathrm{~h}$ prior to infective challenge. Two additional $500 \mu \mathrm{l}$ doses of serum were inoculated 4 and 8 days after challenge. A similar experiment was also performed with transfer of plasma $(200 \mu \mathrm{l})$ from challenged-vaccinated donors, and similar results were obtained.

\subsection{Statistical analysis}

Mann-Whitney $U$ test was used to compare the levels of parasitemia at each time point.

\section{Results}

\subsection{Immunization with $C L-14$ partially protects $\beta 2 m^{-1-}$ mice against infective challenge with a low inoculum}

We have previously shown that immunization with live CL-14-trypomastigotes prevents the mortality and the development of patent parasitemia induced by infective challenge with CL strain (Paiva et al., 1999a). Moreover, this protective immunity can be adoptively transferred with lymphocytes from CL-14-immunized mice, and prior CD8 (but not CD4) depletion abolishes such protective capacity. To assess the role of CD8 lymphocytes in the establishment of this protective immunity, we first immunized $\beta 2$-microglobulin knockout mice $\left(\beta 2 \mathrm{~m}^{-/-}\right)$, which have impaired development of CD8 cells (Koller et al., 1990), with live CL-14-trypomastigotes, and tested their resistance against a challenge with a low dose $\left(10^{2}\right)$ of CL strain blood trypomastigotes.

In agreement with previous results (Tarleton et al., 1996), $\beta 2 \mathrm{~m}^{-/-}$naïve mice developed higher levels of parasitemia than $\beta 2 \mathrm{~m}^{+/+}$naïve controls after infection with $T$. cruzi CL strain $(14,24$, and $26 \mathrm{dpi}, p \leqslant 0.05)$ and died early (Fig. 1). Immune $\beta 2 \mathrm{~m}^{+/+}$did not die or develop any parasitemia after infective challenge. In con-

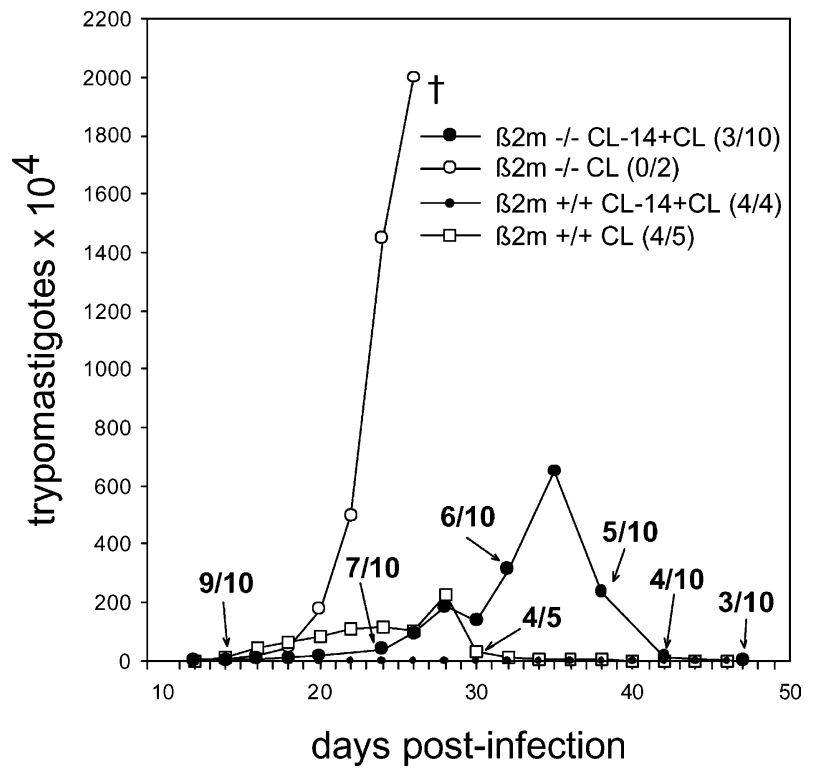

Fig. 1. Immunization with live CL-14-trypomastigotes partially protects $\beta 2 \mathrm{~m}^{-/-}$mice against infective challenge. $\beta 2 \mathrm{~m}^{-/-}$and $\beta 2 \mathrm{~m}^{+/+}$ $\mathrm{BALB} / \mathrm{c}$ mice were immunized with $2 \times 10^{6}-10^{7} \mathrm{CL}-14$-trypomastigotes 6-7 weeks prior to infective challenge with $10^{2}$ trypomastigotes of the CL strain. The proportions of survivors at each time point and 50 days after challenge are indicated on the curves and near the legends, respectively. Females and males were used in equal proportions. Data represent means of parasitemia for 2-10 mice per group.

trast, most of the challenged immune $\beta 2 \mathrm{~m}^{-/-}$mice developed patent parasitemia, but the difference between them and challenged immune $\beta 2 \mathrm{~m}^{+/+}$controls was not statistically significant at most time points (except $24 \mathrm{dpi}, p<0.05$ ). In fact, $30 \%$ of these challenged immune $\beta 2 \mathrm{~m}^{-/-}$mice did not develop any parasitemia and survived infective challenge. As a whole, immune $\beta 2 \mathrm{~m}^{-/-}$mice had a delay in development and lower mean levels of parasitemia than naïve $\beta 2 \mathrm{~m}^{-/-}$mice after infective challenge (24-26 dpi, $p<0.05)$. Even when immune $\beta 2 \mathrm{~m}^{-/-}$mice which had patent parasitemias were compared individually with naive $\beta 2 \mathrm{~m}^{-/-}$mice right before their death, the former had a mean 5 -fold lower levels than the latter. The lower efficiency of immunization among $\beta 2 \mathrm{~m}^{-/-}$than $\beta 2 \mathrm{~m}^{+/+}$mice indicates that antigen presentation by MHC class I is involved in the establishment of protective immunity by live CL-14 parasites, but is not the only mechanism activated by such immunization.

\subsection{Immunization with fixed CL-14-trypomastigotes requires higher doses and longer intervals post-inoculation than live parasites to induce immunity}

The delay in development of parasitemia and the higher proportion of acute phase survival found in challenged immune $\beta 2 \mathrm{~m}^{-/-}$mice compared to infected counterparts indicated that protection could be partially 

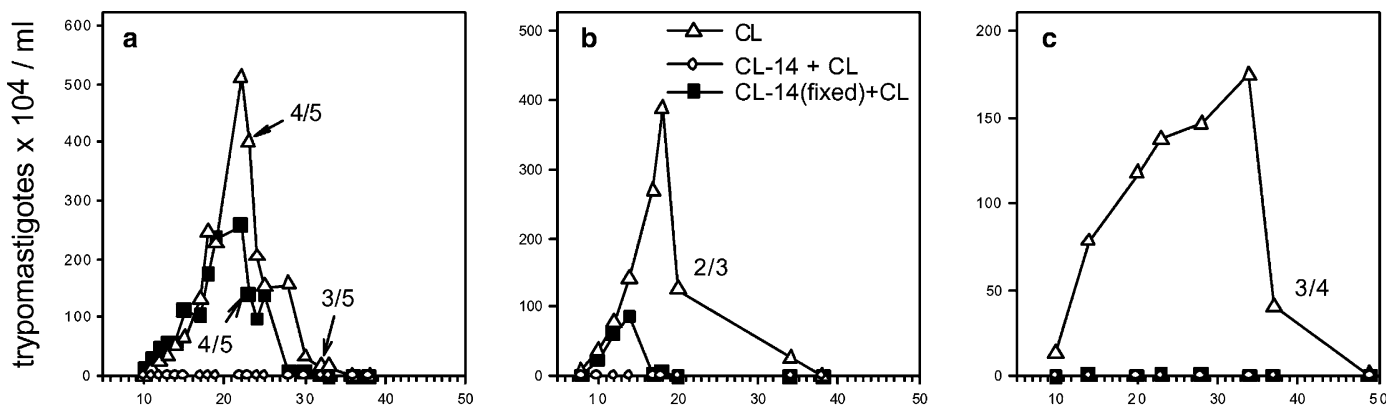

days post-infection

Fig. 2. Efficient immunization with fixed CL-14-trypomastigotes is achieved with optimal doses and time intervals. CL-14-trypomastigotes were fixed in $1 \%$ formaldehyde and used to treat BALB/c mice prior to challenge: $10^{7}$ parasites every 3 weeks ( 3 doses), last dose 3 weeks before challenge (left panel); a single $10^{8}$ dose 4 weeks before challenge (middle panel); a single $10^{8}$ dose 9 weeks before challenge (right panel). Mice were challenged with $10^{4}$ bloodstream trypomastigotes of the CL strain. Data represent means of parasitemia for 3-5 mice per group.

independent of the presentation of cytosolic antigens by MHC class I molecules. To test whether efficient protective immunity could be established in the absence of active cellular invasion by trypomastigotes, we immunized mice with CL-14-trypomastigotes fixed in $1 \%$ formaldehyde-PBS. Then, we challenged mice with $10^{4}$ bloodstream trypomastigotes of the CL strain.

Mice were first immunized with $10^{7}$ fixed CL-14-trypomastigotes, a dose able to induce efficient protective immunity when live parasites are used (Paiva et al., 1999a), boosted with two similar doses applied 3 weeks apart, and challenged 3 weeks later with CL strain trypomastigotes (Fig. 2a). At some timepoints, this treatment produced slightly lower peak levels of parasitemia than those found in naïve controls $(10,15,28$, and $33 \mathrm{dpi}, p<0.05)$. On the other hand, administration of a single 10-fold higher dose $\left(10^{8}\right.$ fixed CL-14-trypomastigotes) followed by infective challenge 4 weeks after treatment, resulted in both early disappearance of patent parasitemia (20 dpi) and no mortality (Fig. 2b). Finally, treatment with a single $10^{8}$ fixed CL-14-trypomastigotes dose followed by infective challenge 9 weeks after immunization resulted in development of very low/absent parasitemia and no mortality (Fig. 2c), while naïve controls presented significantly higher levels of parasitemia $(10-37 \mathrm{dpi}, p<0.05)$ and $25 \%$ mortality within $60 \mathrm{dpi}$. Control mice immunized with a single $10^{7}$ dose of live CL-14-trypomastigotes did not die or develop patent parasitemia (Figs. 2b-c). In other experiments, mice immunized with $10^{8} \mathrm{CL}-14$ fixed trypomastigotes, boosted with $10^{7}$ fixed parasites 4 weeks after the priming dose and challenged 2 weeks after booster dose behaved similar to Fig 2c (data not shown). Taken together, our results demonstrate that immunization with fixed CL-14 parasites can induce efficient protective immunity against infective challenge when optimal immunization regimens are used. Nevertheless, parasite viability lowers the requirements of dose and time to induce immunity.

\subsection{Immunization with live CL-14-trypomastigotes pro- tects perforin-knockout mice against infective challenge}

As CD8 cells from CL-14-immunized mice can confer protective immunity on cell transfer experiments, we evaluated if perforin-mediated cytotoxicity is required as an effector mechanism. Perforin-knockout mice (P0) were immunized with CL-14 and challenged after 6 weeks with a high dose $\left(10^{4}\right)$ of CL strain bloodstream trypomastigotes (Fig. 3). Immune P0 did not die or develop patent parasitemia after challenge, while naïve

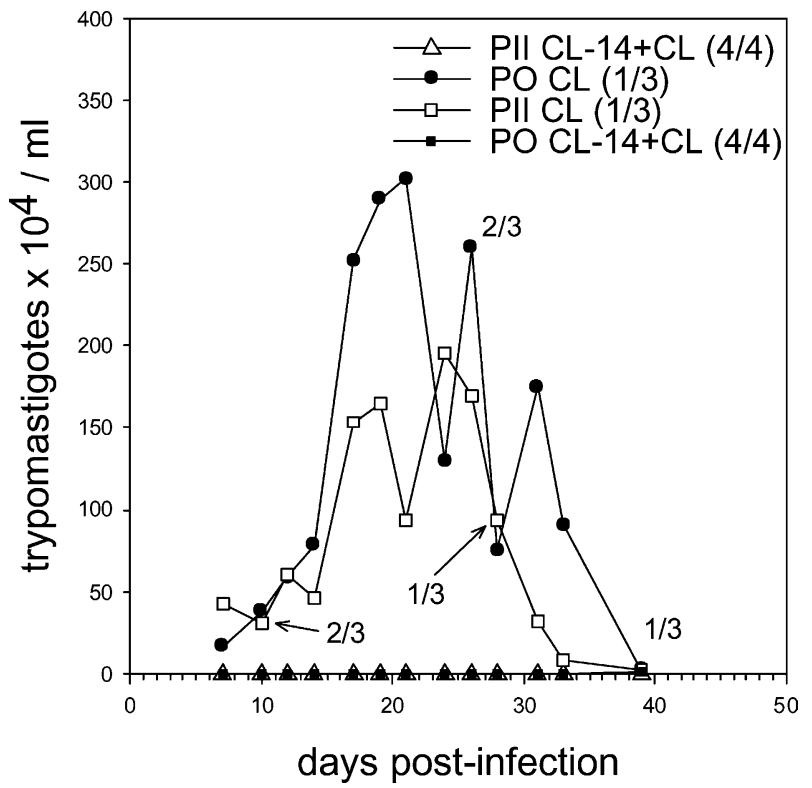

Fig. 3. Immunization with live CL-14-trypomastigotes protects perforin-knockout mice against infective challenge. Perforin-knockout mice (P0) were immunized with $4 \times 10^{6}$ CL-14-trypomastigotes 6 weeks prior to infective challenge with $10^{4}$ trypomastigotes of the $\mathrm{CL}$ strain. The proportions of survivors at each time point and 50 days after challenge are indicated on the curves and near the legends, respectively. Data represent means of parasitemia for 3-4 mice (males) per group. Similar results were obtained in two independent experiments. 
controls developed high levels of parasitemia, (7-31 dpi, $p<0.05$ ) and $2 / 3$ mortality within 50 dpi. Similar data were obtained in two independent experiments. Thus, perforin-knockout mice do benefit from CL-14 immunization, demonstrating that perforin-mediated cytotoxicity is not required as an effector mechanism in the response of immunized mice to challenge.

\subsection{Post-immune in vivo depletion of CD4 or CD8 cells does not interfere with protection, but alters the profile of the humoral response to challenge}

We have previously demonstrated that transfer of immunity with lymphocytes from CL-14-immunized mice can be abolished by prior CD8 (but not CD4) depletion (Paiva et al., 1999a). These data demonstrate that CD8 memory lymphocytes are capable of conferring immunity, but do not elucidate the relevance of this subset to maintenance of immunity in vivo. To evaluate the requirement for $\mathrm{CD} 4$ or $\mathrm{CD} 8$ cells in the response of immunized mice to challenge, we performed a post-immune depletion of these subsets in CL-14-hyperimmunized mice and then challenged them with the CL strain. Also, as a means to analyse the possible contribution of these $\mathrm{T}$ cell subsets as helpers, we evaluated the profile of the humoral response in depleted-immunized mice a month after challenge.

Non-depleted immune controls did not die or develop patent parasitemia after challenge, while naive controls developed high levels of parasitemia and $25 \%$ mortality rate within 30 dpi (Fig. 4a). Similar to non-depleted immune controls, immune mice that had been depleted either of CD4 or CD8 cells before challenge did not die or develop parasitemia, in contrast with naive controls (12-30 dpi, $p<0.05)$. Similar data were obtained in two independent experiments. These results indicate that post-depletion of CD4 or CD8 T cell subsets does not interfere with the protective immunity established after immunization with CL-14.

Immune mice reacted to infective challenge with an increase in plasma titers of anti-T. cruzi IgG1 $30 \mathrm{dpi}$ (14.8-fold). Titers found in challenged immune mice were far higher (105-fold) than that found in infected naive controls (Fig. 4b), while depletion of CD4 or CD8 cells prior to infective challenge reduced this increase (4.86- and 5.2-fold the levels in immunized mice, respectively). Plasma titers of anti- $T$. cruzi IgG2a in challenged immune mice were slightly higher than in infected naïve controls (1.4-fold), and also higher than in immunized only mice (3-fold). Depletion of CD4 or CD8 cells prior to challenge produced an increase in IgG2a titers above the levels found in challenged immune mice (2.93- and 1.94-fold, respectively). These results suggest that both $\mathrm{CD} 4$ and $\mathrm{CD} 8$ subsets act to regulate the switch to $\mathrm{IgG} 1$ isotype in the response of CL-14-immunized mice to infective challenge.
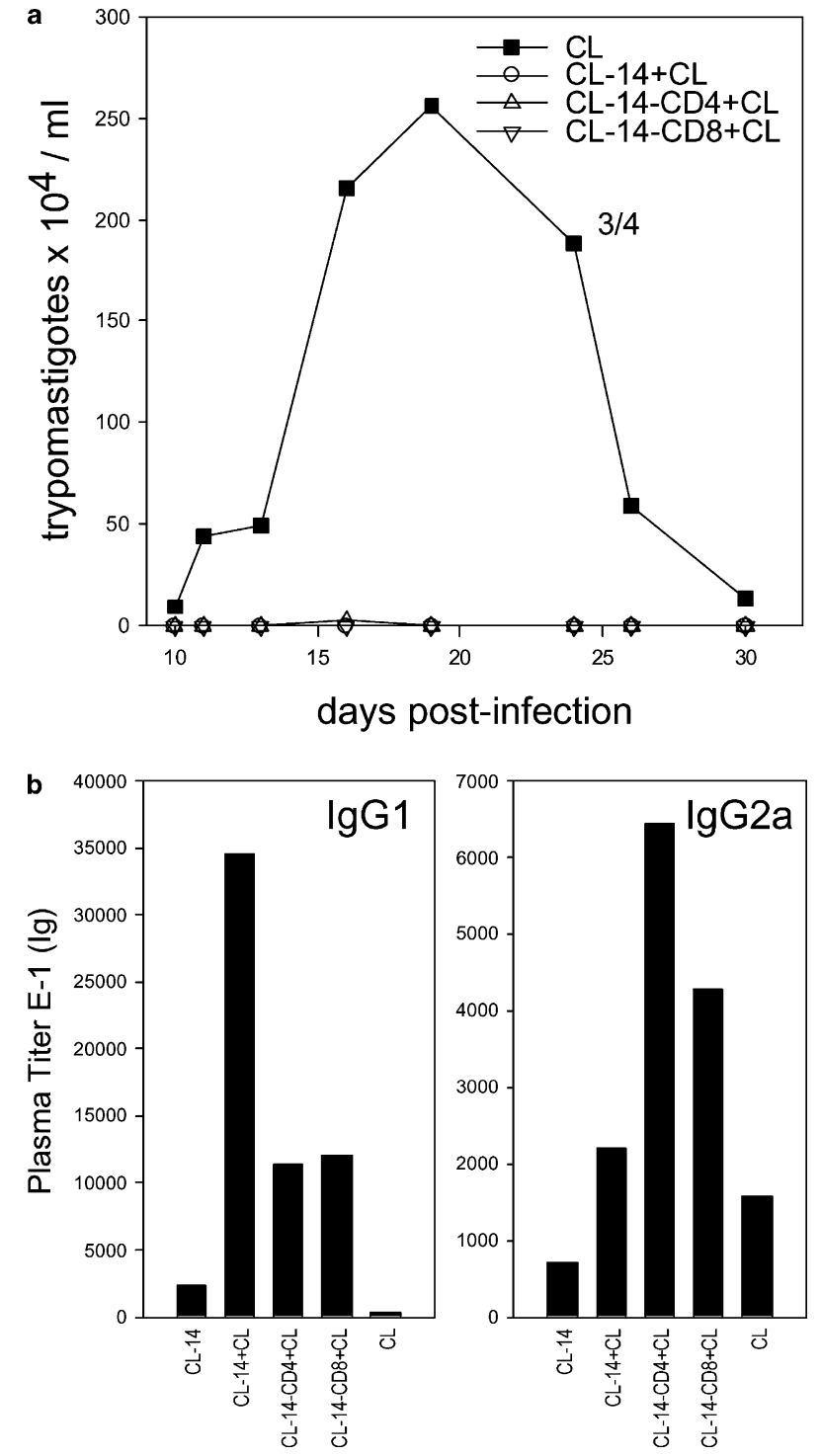

Fig. 4. Post-immune depletion of CD4 or CD8 cells from CL-14-immunized mice does not interfere with protection. Hyperimmunized $\mathrm{BALB} / \mathrm{c}$ mice $\left(10^{7} \mathrm{CL}-14\right.$-trypomastigotes on week $12,2 \times 10^{6}$ on week 4 before challenge) received daily $0.5 \mathrm{mg}$ of purified anti-CD8 (53.6.7) or anti-CD4 (GK1.5) i.p. on days 4, 3, and 2 before challenge with $10^{4}$ trypomastigotes of the CL strain. Upper panel represents mean of parasitemia for $4-5$ mice (females) per group. Mortality is indicated on the curve. Similar results were obtained in two independent experiments. Lower panel represents the titers of anti- $T$. cruzi $\mathrm{IgG} 1$ and IgG2a antibodies in the plasma of the groups of mice shown above (pooled) 30 days after infective challenge. Titers for CL-14-hyperimmunized mice are also shown. The antigenic suspensions in these ELISA assays were composed of 90\% amastigote and 10\% trypomastigote forms.

\subsection{Total body irradiation causes late impairment in the ability of CL-14-immunized mice to clear parasitemia}

The presence of high serum titers of anti-T. cruzi antibodies in immunized mice (Pyrrho et al., 1998) suggested that the humoral response plays an important role in this protective immunity. To test whether 
lymphoid impairment could render immunized mice susceptible to infective challenge, we first irradiated groups of adult naïve and hyperimmune mice with $600 \mathrm{rad}$. This dose of irradiation is known to eliminate most of the lymphoid cells in the spleen and lymph nodes of $\mathrm{BALB} / \mathrm{c}$ mice while preserving long-lived bone marrow plasma cells alive (Slifka and Ahmed, 1996), and was able to deplete most $\mathrm{CD} 8^{+}$and $\mathrm{B}$ lymphocytes from our naïve and immune mice (evaluated 4 days after irradiation). A day after irradiation, we challenged both groups of mice with $10^{3} \mathrm{CL}$ strain bloodstream trypomastigotes. Then, mice received isogenic bone marrow transplantation (BMT) with cells from normal donors 3 or 7 days after infective challenge. To exclude the possibility that priming of remaining naïve lymphocytes (recently matured or transferred with BM) by residual CL-14 antigens conferred immunity, a group of naïve irradiated mice were immunized with CL-14 $1 \mathrm{~h}$ after BMT (performed $7 \mathrm{dpi}$ ).

Irradiated naïve mice (Fig. 5a) developed significantly higher levels of parasitemia than non-irradiated naïve counterparts $(10-17 \mathrm{dpi}, p<0.05)$, and $75 \%$ did not survive infective challenge, unlike non-irradiated naive controls $(25 \%$ mortality). The single irradiated naïve mouse that survived acute infection $(>60 \mathrm{dpi})$ presented very high levels of parasitemia. Thus, the immune response to an infective challenge with $10^{3}$ bloodstream trypomastigotes was severely impaired by irradiating naïve mice. Conversely, irradiated immune mice had a higher rate of survival $(80 \%)$ than that irradiated naive mice $(25 \%)$. However, irradiated immune mice developed very low levels of parasitemia starting $17 \mathrm{dpi}$ (maximum: $6.27 \times 10^{4} / \mathrm{ml}$ ), far lower than in irradiated naïve controls $(10-21 \mathrm{dpi}, p<0.05)$ or in non-irradiated naïve mice $(14-43 \mathrm{dpi}, p<0.05)$. Non-irradiated immune controls did not die or developed any detectable parasitemia after challenge. All irradiated naïve mice that received isogenic BMT along with CL-14-trypomastigotes $7 \mathrm{dpi}$ were dead by $25 \mathrm{dpi}$ after developing far higher parasitemias (260-fold, $19 \mathrm{dpi}$ ) than irradiated immune mice repopulated $7 \mathrm{dpi}(10-19 \mathrm{dpi}, p<0.05)$. These later results argue against the possibility that priming of naïve lymphocytes by CL-14 antigens at this moment after CL infection ( $7 \mathrm{dpi}$ ) could prevent acute parasitemia.

In a second approach, we used a 10-fold higher dose of $\mathrm{CL}$ strain trypomastigotes to challenge mice. Hyperimmune mice and naive controls were irradiated with $515 \mathrm{rad}$. All mice were challenged with $10^{4}$ trypomastigotes of the CL strain $6 \mathrm{~h}$ after irradiation and received isogenic BMT $24 \mathrm{~h}$ later (Fig. 5b). After infective challenge, irradiated naïve mice developed high parasitemias and were all dead by $20 \mathrm{dpi}$, in contrast with non-irradiated naïve controls, which had $20 \%$ mortality and far lower parasitemias $(12-17 \mathrm{dpi}, p<0.05)$. Irradiated immune mice had patent parasitemia since $10 \mathrm{dpi}$,

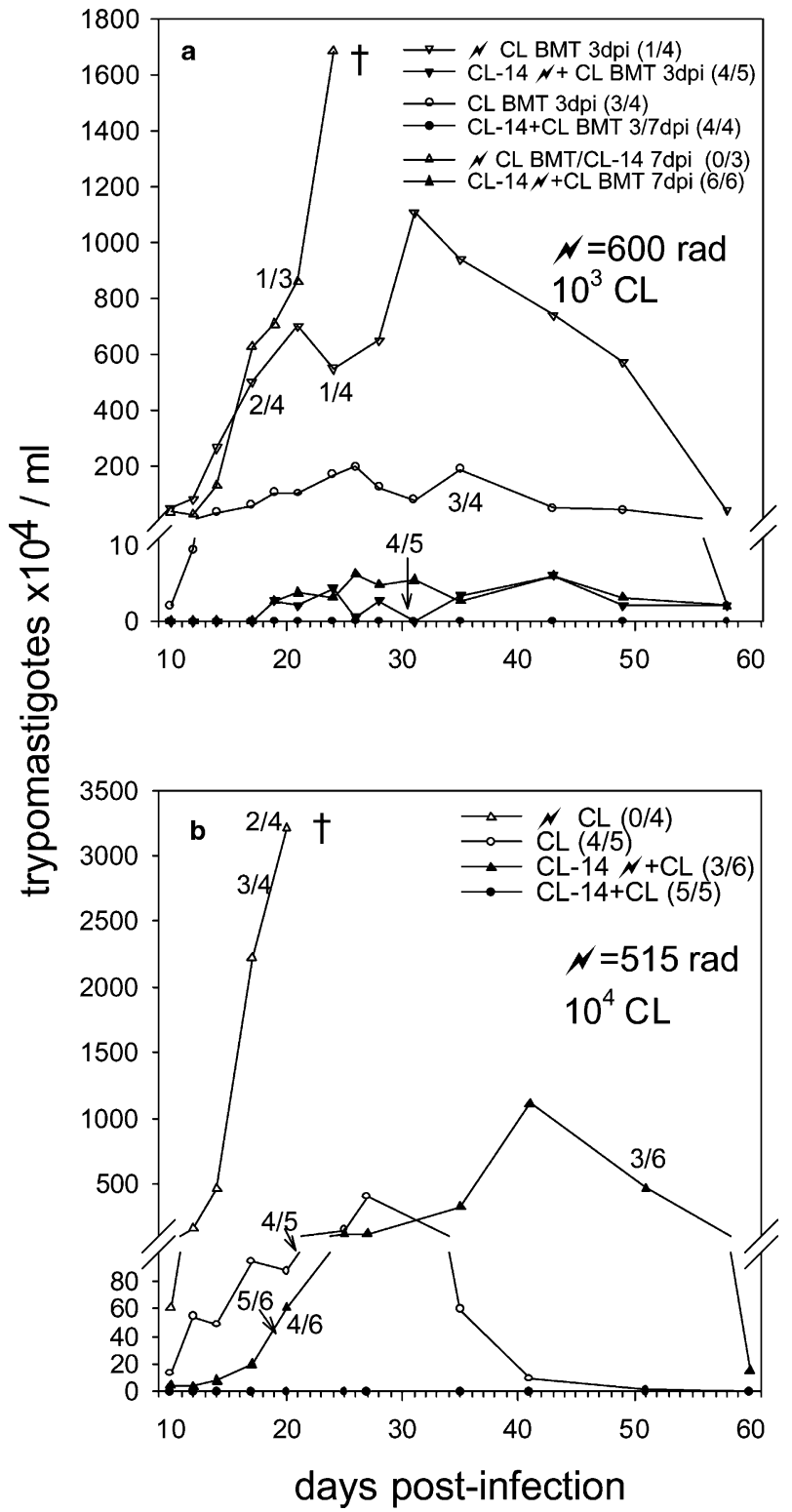

Fig. 5. Post-immune sublethal irradiation of CL-14-immunized mice prior to challenge causes late impairment in the control of parasitemia. (a) Non-treated and hyperimmunized female BALB/c mice $\left(10^{7} \mathrm{CL}\right.$ 14-trypomastigotes i.p. 6 and 3 weeks prior to irradiation) were challenged i.p. with $10^{3} \mathrm{CL}$ strain trypomastigotes a day after irradiation $(600 \mathrm{rad})$. All mice received BMT $\left(2 \times 10^{7}\right.$ bone marrow cells) from normal donors 3 or 7 days after challenge, as indicated in the figure. A group of irradiated normal mice received $10^{7} \mathrm{CL}$-14-trypomastigotes i.p. $1 \mathrm{~h}$ after bone marrow cell transplantation $(\boldsymbol{N}+\mathrm{CL}$ BMT $+\mathrm{CL}-14$ $7 \mathrm{dpi})$. (b) Non-treated and hyperimmunized male BALB/c mice $\left(10^{7}\right.$ CL-14-trypomastigotes i.p. 7 and 3 weeks prior to irradiation) were challenged i.p. with $10^{4} \mathrm{CL}$ strain trypomastigotes a day after irradiation $(515 \mathrm{rad})$. All mice received BMT $\left(2 \times 10^{7}\right.$ bone marrow cells $)$ from normal donors a day after challenge. Data represent means of parasitemia for 3-6 mice per group. The proportions of survivors at each time point and 50 days after challenge are indicated on the curves and near the legends, respectively.

but kept it far lower than irradiated naive controls (12$17 \mathrm{dpi}, p<0.05)$ and even lower than non-irradiated naïve mice until $17 \mathrm{dpi}(10-17 \mathrm{dpi}, p \leqslant 0.05)$. Then their 


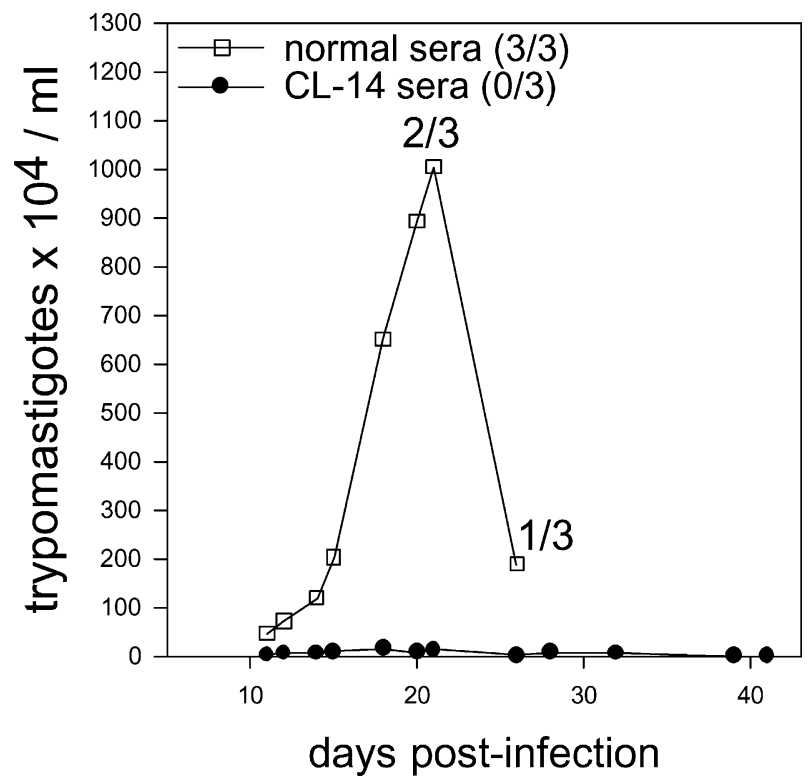

Fig. 6. Transfer of serum from CL-14-immunized donors protects naïve mice against challenge. Sera $(0.5 \mathrm{ml})$ from hyperimmunized female BALB/c mice ( $10^{7}$ CL-14-trypomastigotes on weeks 6 and 3 before sacrifice) or sex and age-matched controls were transferred i.p. to naïve female receptors (6-8 weeks) $1 \mathrm{~h}$ before challenge with $10^{3} \mathrm{CL}$ blood trypomastigotes, and also on days 4 and 8 post-challenge. Graph represents mean of parasitemia for three mice per group. The proportions of survivors at each time point and 40 days after challenge are indicated on the curves and near the legends, respectively.

parasitemia rose, in contrast with non-irradiated immune mice, which kept the parasitemias negative all the time $(10-12$ and $25-60 \mathrm{dpi}, p<0.05 ; 14-20 \mathrm{dpi}, p=$ 0.07). Half of irradiated immune mice were dead by $60 \mathrm{dpi}$, different from non-irradiated immune mice. Survivors controlled parasitemia by $60 \mathrm{dpi}$, when normal leukograms were re-established (data not shown), but at this time point they still had higher parasitemias than non-irradiated naive controls $(p<0.05)$ and overt clinical signs of disease such as rough fur, prostration, and hypotonia. Acute phase survivors were still alive $100 \mathrm{dpi}$.

\subsection{Passive transfer of serum from immune donors confers protection to naïve receptors}

We tested whether serum from vaccinated donors was able to confer protection when passively transferred to naïve receptors. Receptors of immune serum developed lower parasitemia than receptors of normal serum (11$18 \mathrm{dpi}, p<0.05 ; 20-21 \mathrm{dpi} p=0.08$ ) and survived acute phase. Receptors of normal serum died before $30 \mathrm{dpi}$ (Fig. 6).

\section{Discussion}

It is clear that as a general rule, $\beta 2 \mathrm{~m}^{-/-}$mice do not develop efficient actively induced or natural immunity to control acute T. cruzi infection (Kumar and Tarleton, 1998; Miller et al., 1997; Tarleton et al., 1992). Moreover, other CD8-deficient mice, such as CD8 knockout, $\mathrm{TAP}^{-1-}$ and anti-CD8 treated mice also fail to survive acute infection (Kumar and Tarleton, 1998; Rottenberg et al., 1995; Tarleton, 1990) or benefit from immunization (Kumar and Tarleton, 1998; Tarleton, 1990). Yet, the mechanisms by which CD8 cells contribute to control acute infection are not clear. In this paper, we demonstrated that $\beta 2 \mathrm{~m}^{-/-}$mice benefit far less from immunization with CL-14 than perforin-knockout mice. These results reinforce the notion that the participation of CD8 cells is required to the establishment of efficient anti-T. cruzi immunity and is independent from its capacity to generate perforin-mediated effector responses. Nevertheless, a general delay in development of parasitemia and mortality was observed in challenged-immunized $\beta 2 \mathrm{~m}^{-/-}$mice, besides a certain degree of complete protection against acute infection after challenge with a low inoculum of CL strain. Similarly, $\beta 2 \mathrm{~m}^{-/-}$mice immunized with paraflagellar rod protein had decreased parasitemias after virulent challenge with a high inoculum, despite their early death (Miller et al., 1997). These results indicate that mechanisms elicited by immunization other than CD8 activation can act to protect these mice.

CD8 cells can act as by-stander helper cells to production of antibodies (Mosmann et al., 1997). In this regard, it has been previously demonstrated that both $\beta 2 \mathrm{~m}^{-/-}$and MHC class II knockout mice have deficient production of anti-T. cruzi antibodies (Tarleton et al., 1996), suggesting that both CD4 and CD8 T cell subsets are involved in B cell help in this infection. Our results also indicate that both CD4 and CD8 cells are involved in the regulation of anti- $T$. cruzi antibodies production, as their depletion prevents the increase in titers of antiT. cruzi IgG1 and determines an increase in titers of IgG2a in the response of immunized mice to challenge. Thus, a possible explanation to these data is that the production of $\mathrm{IgG} 2 \mathrm{a}$ is regulated by a $\mathrm{T} 1$ population of non-CD4 and non-CD8 cells, which is partially repressed by T2 CD4 and CD8 T cell subsets (promoters of IgG1 production) during the response of immunized mice to challenge. Also, IFN- $\gamma$-independent production of anti-T. cruzi $\mathrm{IgG} 2 \mathrm{a}$ was recently described (Holscher et al., 1998; Markine-Goriaynoff et al., 2000), and could be involved in the production of IgG2a by $\mathrm{T}$ cell depleted mice. It must be emphasized, however, that postimmune depletion of CD4 or CD8 subsets still allowed higher titers of IgG1 than that present in CL-infected and far higher IgG2a titers, which could explain the maintenance of a highly effective protective immunity. Further studies are still required to elucidate the mechanisms by which help proceeds in CL-14-immunized mice and its putative role in the establishment of immunity by immunization. 
The partial maintenance of immunity after irradiation of CL-14-immunized mice could be explained by three non-mutually exclusive hypotheses: (i) rapid priming of recently matured lymphocytes or BM mature lymphocytes by residual CL-14 antigens in secondary lymphoid organs; (ii) expansion of surviving memory cells as a recall response to presentation of CL antigens; and/or (iii) remaining humoral response. As a control to the priming of naïve lymphocytes (recently matured or transferred with $\mathrm{BM}$ ) by residual antigens, we compared CL-14-immunized mice that had been irradiated with $600 \mathrm{rad}$ (BMT $7 \mathrm{dpi}$ ) and then challenged with naïve mice that were irradiated, challenged, and received CL14-trypomastigotes an hour after isogenic BMT (7 dpi). Our results indicate that CL-14 antigens cannot prime sufficient lymphocytes in this interval such as to prevent acute parasitemia, arguing against the first hypothesis. Moreover, we must recall that only when challenged 4 weeks after being immunized, animals do acquire complete protection against development of parasitemia (Paiva et al., 1999a), indicating that priming of large numbers of naive lymphocytes and/or the production of specific anti- $T$. cruzi antibodies are required to efficient protection. The re-expansion of surviving memory $\mathrm{T}$ cells in irradiated CL-14-immunized mice induced by $\mathrm{CL}$ antigens cannot be ruled out by our data, since it has been recently demonstrated that lymphoid cells can be rescued from in vivo sublethal irradiation (550-600 rad) by early TCR stimulation (Sechler et al., 1999). Nevertheless, it seems unlikely that remaining memory $\mathrm{T}$ lymphocytes could expand so quickly such as to get sufficient effector lymphocytes to control parasite growth shortly after challenge, keeping irradiated animals protected since $10 \mathrm{dpi}$, but later (from $17 \mathrm{dpi}$ ) lose control and gradually allow the development of parasitemia. Rather, our data suggest that protective resources were spent in the defense against the parasite, what would also explain the higher parasitemias and mortality rates found in irradiated immune mice challenged with a higher inoculum. Thus, we speculate that parasitemia is mainly controlled by specific antibodies left in the sera after irradiation and possibly replaced by long-lived plasma cells (Slifka and Ahmed, 1996). In fact, total IgG titers were still high in irradiated immune mice 62 dpi (data not shown). Such remaining humoral response would slow down the invasion of distant cells but would not eliminate parasite reservoirs or prevent cell-to-cell contamination. In this case, the development of late parasitemia and mortality in irradiated immune mice would result from fading of the humoral response after lymphoid impairment and increased release of parasites from intracellular reservoirs.

What is the relative contribution of CD8 T cells versus humoral immunity to survival and to the control of parasite burden induced by infective challenge? This question has been addressed previously in mice immu- nized with avirulent M80 clone (Kumar and Tarleton, 1998). It seems to us that despite the different immunizing properties of CL-14 and M80, we have found similar answers. The failure of $\beta 2 \mathrm{~m}^{-/-}$mice to be completely protected against acute infection after immunization with CL-14 points towards participation of CD8 cells in the establishment of immunity. On the other hand, once immunity is established, although CD8 cells still function to protect against virulent $T$. cruzi (Paiva et al., 1999a), punctual depletion of CD8 immune compartment does not interfere with immunity, as it does in other model (Miyahira et al., 1999). Moreover, lymphoid impairment by 515-600 rad total body irradiation only partially broke the protective immunity that controls parasitemia and allows survival of CL-14immunized mice, suggesting the participation of the humoral response in this process, as discussed in the paragraph above. In fact, the existence of a strong humoral response against $T$. cruzi dominated especially by the production of $\mathrm{IgG1}$, but also $\operatorname{IgG} 2 \mathrm{a}$, and passively transferred with sera, has been verified by us in CL-14immunized mice. Thus, the proposition that a strong humoral response against $T$. cruzi (preserved even after $\mathrm{CD}^{+} \mathrm{T}$ cell depletion) is the basis of immunity in chronically infected mice (Rottenberg et al., 1992; Tarleton, 1990) despite the existence of a functional CD8 immunity, seems to fit immunization with CL-14 as well. These data also differ from those obtained from mice immunized with the avirulent trypomastigotes of Corpus Christi strain (Tarleton, 1990) and epimastigotes of the PF strain (Ribeiro-dos-Santos et al., unpublished), in which protective response to challenge could be totally abolished by sustained post-immune CD8 depletion.

Immunization against $T$. cruzi has been disregarded as a possible prophylactic measure due to the general low efficiency, induction of immune abnormalities (Pestel et al., 1992; Tarleton et al., 1981) and even heart disease (Motran et al., 1998; Motran et al., 1999; Ruiz et al., 1985) by experimental procedures. On the other hand, some other counter-examples evidence that immunization can be a safe and efficient measure against T. cruzi (Andrews et al., 1985; Basombrio and Besuschio, 1982; Basombrio et al., 1982; Lima et al., 1991). The simplest explanation to these contrasting findings in the literature is that the differences in the nature of various $T$. cruzi antigenic preparations may either induce the development of strong protective immunity and/or predispose to undesirable responses, probably by generating immunosuppression or polyclonal lymphocyte activation. Also, the key to such a paradox may lie in the protocol of immunization used, which can act to reinforce some immune mechanisms and/or not allow others to be activated. In this regard, we believe that the antigenic diversity and the activation of both cellular and humoral immune mechanisms provided by immu- 
nization with clone CL-14 contribute for the strong protective immunity against $T$. cruzi it generates.

\section{Acknowledgments}

This work was supported by FAPERJ, PRONEX CNPq, and WHO (Grant 960853). CNP was supported by CNPq (Ph.D.) and FAPERJ (post-doctoral) fellowships. We thank Drs. Alberto Nobrega for helpful discussions and Drs. Marcelo Bozza and Richard Sachsse for careful review of the manuscript.

\section{References}

Andrews, N.W., Alves, M.J., Schumacher, R.I., Colli, W., 1985. Trypanosoma cruzi: protection in mice immunized with 8-methoxypsoralen-inactivated trypomastigotes. Experimental Parasitology $60,255-262$.

Araguth, M.F., Rodrigues, M.M., Yoshida, N., 1988. Trypanosoma cruzi metacyclic trypomastigotes: neutralization by the stagespecific monoclonal antibody $1 \mathrm{G} 7$ and immunogenicity of $90 \mathrm{kD}$ surface antigen. Parasite Immunology 10, 707-712.

Araujo, F.G., Morein, B., 1991. Immunization with Trypanosoma cruzi epimastigote antigens incorporated into iscoms protects against lethal challenge in mice. Infection and Immunity 59, 2909-2914.

Basombrio, M.A., Besuschio, S., 1982. Trypanosoma cruzi culture used as vaccine to prevent chronic Chagas' disease in mice. Infection and Immunity 36, 351-356.

Basombrio, M.A., Besuschio, S., Cossio, P.M., 1982. Side effects of immunization with liver attenuated Trypanosoma cruzi in mice and rabbits. Infection and Immunity 36, 342-350.

Brener, Z., 1962. Therapeutic activity and criterium of cure on mice experimentally infected with Trypanosoma cruzi. Revista do Instituto de Medicina Tropical de São Paulo 4, 389.

Brener, Z., Chiari, E., 1963. Variações morfológicas observadas em diferentes amostras de Trypanosoma cruzi. Revista do Instituto de Medicina Tropical de São Paulo 5, 220-240.

Chiari, E., 1981. Diferenciação do Trypanosoma cruzi em cultura. Ph.D. thesis. Universidade Federal de Minas Gerais, Belo Horizonte, MG, Brasil.

DosReis, G.A., 1997. Cell-mediated immunity in experimental Trypanosoma cruzi infection. Parasitology Today 13, 335-342.

Gonzalez, J., Araguth, M.F., Yoshida, N., 1991. Resistance to acute Trypanosoma cruzi infection resulting from immunization of mice with a 90-kilodalton antigen from metacyclic trypomastigotes. Infection and Immunity 59, 863-867.

Hoft, D.F., Schnapp, A.R., Eickhoff, C.S., Roodman, S.T., 2000. Involvement of CD4(+) Th1 cells in systemic immunity protective against primary and secondary challenges with Trypanosoma cruzi. Infection and Immunity 68, 197-204.

Holscher, C., Kohler, G., Muller, U., Mossmann, H., Schaub, G.A., Brombacher, F., 1998. Defective nitric oxide effector functions lead to extreme susceptibility of Trypanosoma cruzi-infected mice deficient in gamma interferon receptor or inducible nitric oxide synthase. Infection and Immunity 66, 1208-1215.

Koller, B.H., Marrack, P., Kappler, J.W., Smithies, O., 1990. Normal development of mice deficient in beta $2 \mathrm{M}$, MHC class I proteins, and CD8+ T cells. Science 248, 1227-1230.

Kumar, S., Tarleton, R.L., 1998. The relative contribution of antibody production and $\mathrm{CD} 8+\mathrm{T}$ cell function to immune control of Trypanosoma cruzi. Parasite Immunology 20, 207-216.
Lima, M.T., Jansen, A.M., Rondinelli, E., Gattass, C.R., 1991. Trypanosoma cruzi: properties of a clone isolated from CL strain. Parasitology Research 77, 77-81.

Lima, M.T., Lenzi, H.L., Gattass, C.R., 1995. Negative tissue parasitism in mice injected with a noninfective clone of Trypanosoma cruzi. Parasitology Research 81, 6-12.

Markine-Goriaynoff, D., Der Logt, J.T., Truyens, C., Nguyen, T.D., Heessen, F.W., Bigaignon, G., Carlier, Y., Coutelier, J.P., 2000. IFN-gamma-independent $\operatorname{IgG} 2$ a production in mice infected with viruses and parasites. International Immunology 12, 223-230.

Miller, M.J., Wrightsman, R.A., Manning, J.E., 1996. Trypanosoma cruzi: protective immunity in mice immunized with paraflagellar rod proteins is associated with a T-helper type 1 response. Experimental Parasitology 84, 156-167.

Miller, M.J., Wrightsman, R.A., Stryker, G.A., Manning, J.E., 1997. Protection of mice against Trypanosoma cruzi by immunization with paraflagellar rod proteins requires $\mathrm{T}$ cell, but not $\mathrm{B}$ cell, function. Journal of Immunology 158, 5330-5337.

Miyahira, Y., Kobayashi, S., Takeuchi, T., Kamiyama, T., Nara, T., Nakajima-Shimada, J., Aoki, T., 1999. Induction of CD8+ T cellmediated protective immunity against Trypanosoma cruzi. International Immunology 11, 133-141.

Mosmann, T.R., Li, L., Sad, S., 1997. Functions of CD8 T-cell subsets secreting different cytokine patterns. Seminars in Immunology 9 , $87-92$.

Motran, C.C., Cerban, F.M., Rivarola, H.W., Vottero de Cima, E., 1999. Characterization of autoantibodies generated in mice by immunization with the C-terminal region of Trypanosoma cruzi ribosomal P1 and P2 proteins. Clinical Immunology 91, 17-24.

Motran, C.C., Cerban, F.M., Rivarola, H.W., Iosa, D., Vottero de Cima, E., 1998. Trypanosoma cruzi: immune response and functional heart damage induced in mice by the main linear B-cell epitope of parasite ribosomal $\mathrm{P}$ proteins. Experimental Parasitology $88,223-230$.

Paiva, C.N., Castelo-Branco, M.T., Lannes-Vieira, J., Gattass, C.R., 1999a. Trypanosoma cruzi: protective response of vaccinated mice is mediated by $\mathrm{CD} 8+$ cells, prevents signs of polyclonal $\mathrm{T}$ lymphocyte activation, and allows restoration of a resting immune state after challenge. Experimental Parasitology 91, 7-19.

Paiva, C.N., Castelo-Branco, M.T., Rocha, J.A., Lannes-Vieira, J., Gattass, C.R., 1999b. Trypanosoma cruzi: lack of T cell abnormalities in mice vaccinated with live trypomastigotes. Parasitology Research 85, 1012-1017.

Pestel, J., Defoort, J.P., Gras-Masse, H., Afchain, D., Capron, A., Tartar, A., Ouaissi, A., 1992. Polyclonal cell activity of a repeat peptide derived from the sequence of an 85-kilodalton surface protein of Trypanosoma cruzi trypomastigotes. Infection and Immunity 60, 715-719.

Pyrrho, A.S., Moraes, J.L., Peçanha, L.M., Gattass, C.R., 1998. Trypanosoma cruzi: $\mathrm{IgG1}$ and $\mathrm{IgG} 2 \mathrm{~b}$ are the main immunoglobulins produced by vaccinated mice. Parasitology Research 84, 333-337.

Quanquin, N.M., Galaviz, C., Fouts, D.L., Wrightsman, R.A., Manning, J.E., 1999. Immunization of mice with a TolA-like surface protein of Trypanosoma cruzi generates CD4(+) T-celldependent parasiticidal activity. Infection and Immunity 67, $4603-4612$.

Ribeiro-dos-Santos, R., Rassi, A., Köberle, F., 1981. Chagas' disease. In: Schonfeld, H. (Ed.), Antiparasitic Chemotherapy. S. Karger, Basel, pp. 115-134.

Rodrigues, M.M., Ribeirao, M., Pereira-Chioccola, V., Renia, L., Costa, F., 1999. Predominance of CD4 Th1 and CD8 Tc1 cells revealed by characterization of the cellular immune response generated by immunization with a DNA vaccine containing a Trypanosoma cruzi gene. Infection and Immunity 67, 3855-3863.

Rottenberg, M.E., Riarte, A., Sporrong, L., Altcheh, J., Petray, P., Ruiz, A.M., Wigzell, H., Orn, A., 1995. Outcome of infection with 
different strains of Trypanosoma cruzi in mice lacking CD4 and/or CD8. Immunological Letters 45, 53-60.

Rottenberg, M.E., Rodriguez, D.A., Orn, A., 1992. Control of Trypanosoma cruzi infection in mice deprived of T-cell help. Scandinavian Journal of Immunology 36, 261-268.

Ruiz, A.M., Esteva, M., Cabeza, M., Laguens, R.P., Segura, E.L., 1985. Protective immunity and pathology induced by inoculation of mice with different subcellular fractions of Trypanosoma cruzi. Acta Tropica 42, 299-309.

Sechler, J.M., Hansal, S.A., Morris, D.I., McFarland, H.I., Rosenberg, A.S., 1999. Antigen presentation determines the fate of the T memory response in vivo after sublethal gamma-irradiation. Journal of Immunology 163, 4701-4706.

Slifka, M.K., Ahmed, R., 1996. Long-term antibody production is sustained by antibody-secreting cells in the bone marrow following acute viral infection. Annals of the New York Academy of Science 797, 166-176.

Tarleton, R.L., 1990. Depletion of CD8+ T cells increases susceptibility and reverses vaccine-induced immunity in mice infected with Trypanosoma cruzi. Journal of Immunology 144, 717-724.

Tarleton, R.L., Grusby, M.J., Postan, M., Glimcher, L.H., 1996. Trypanosoma cruzi infection in MHC-deficient mice: further evidence for the role of both class I- and class II-restricted T cells in immune resistance and disease. International Immunology 8, $13-22$.

Tarleton, R.L., Koller, B.H., Latour, A., Postan, M., 1992. Susceptibility of beta 2-microglobulin-deficient mice to Trypanosoma cruzi infection. Nature 356, 338-340.

Tarleton, R.L., Kuhn, R.E., Cunningham, D.S., 1981. Mitomycin Ctreated Trypanosoma cruzi in vaccination of mice: induction of immunosuppression but not protection. Infection and Immunity 31, 693-697.

Umezawa, E.S., Stolf, A.M., Zingales, B., 1993. Trypanosoma cruzi: different surface antigens of trypomastigotes are targets of lytic antibodies. Acta Tropica 54, 41-53.

Walsh, C.M., Matloubian, M., Liu, C.C., Ueda, R., Kurahara, C.G., Christensen, J.L., Huang, M.T., Young, J.D., Ahmed, R., Clark, W.R., 1994. Immune function in mice lacking the perforin gene. Proceedings of the National Academy of Science USA 91, 10854-10858.

Wizel, B., Nunes, M., Tarleton, R.L., 1997. Identification of Trypanosoma cruzi trans-sialidase family members as targets of protective CD8+ TC1 responses. Journal of Immunology 159, $6120-6130$ 